\title{
Research on fine boring simulation based on squeezed liquid film damper
}

\author{
Qiang Shao ${ }^{1,3}$, Dong Wang ${ }^{2}$, Ping-shu Ge $e^{1,3}$ and Le Wang ${ }^{2^{*}}$
}

\begin{abstract}
The liquid film damping is one of the main technology for the aerospace, navigation, and machine tool. However, the research on the fine boring is very limited. The paper set up the fine boring squeezed liquid film damped system of multi degree of freedom vibration simulation model and solve mathematical model by transfer matrix theory. The damping coefficient for the fine boring system can be obtained. The mechanical device of liquid film damping system is established. 20\# machine oil, 40\# machine oil, and cutting fluid are used to the system. The tests indicate that the effect of liquid film formed by cutting fluid is better than oil film formed by machine oil in the static test, but oil film formed by machine oil is better than liquid film formed by cutting fluid in the effect of dynamic test. The simulation model has high accuracy to reliability. The simulation model can directly obtain the optimal parameters, so as to provide effective way to guide field processing.
\end{abstract}

Keywords: Fine boring, Squeezed liquid film, Damp, System simulation

\section{Introduction}

At present, the liquid film damping technology has widely research and application in the areas such as aerospace and machine tool [1-4]. But the liquid film (including oil film) damping technique is applied to fine boring processing at home and abroad for the first time. And the fine boring liquid film damping system can be carried on through the theoretical analysis and experimental research. A reasonable mathematical model for simulation is established on the basis of the direct analysis on the influence on many parameters of the system [5-8]. So the parameter optimization and the excellent fine boring liquid film damping of shock absorber are designed.

Fine boring liquid film damping system has a simple structure. The inside and outside of the damper is filled with liquid. Under the condition of high-speed rotation, a squeezed liquid film is formed between the workpiece and damping sleeve because of the boring bar's lateral vibration. At the same time, the damping force is produced for preventing the gap between the workpiece and the damping. So it can consume vibration energy of the boring bar, reduce the amplitude, and improve the machining quality of fine boring.

\footnotetext{
* Correspondence: sq@dlnu.edu.cn

${ }^{2}$ College of Engineering Education, Dalian Minzu University, Dalian 116600, China Full list of author information is available at the end of the article
}

\section{Methodology}

Over the years, many experts and scholars at home and abroad devoted themselves to the boring bar dynamics analysis. But most of them were based on a single degree of freedom vibration system. The influence of the main modes on more degree of freedom system is ignored because of single degree of freedom system in the vibration of the system. So the analyses of the system are not accurate enough. In this paper, the author will consider the fine boring squeeze liquid film damping system as a multiple degree of freedom vibration system [9-11], and it can significantly improve the accuracy of the vibration analysis. Its dynamic model has lots of types, including: (1) lumped parameter model, (2) distributed parameter model, and (3) hybrid parameter model. To analyze the vibration characteristics of boring bar concrete parts, the paper use the lumped parameter model. This tool location can be regarded as inelastic quality unit for vibration characteristic analysis [12]. The law of the system vibration is concluded more accurately.

Each part of the boring bar length and the diameter number is as follows: $L_{1}=40 \mathrm{~mm}, D_{1}=56 \mathrm{~mm} ; L_{2}=100 \mathrm{~mm}$, $D_{2}=40 \mathrm{~mm} ; L_{3}=100 \mathrm{~mm}, D_{3}=40 \mathrm{~mm}$; and $L_{4}=40 \mathrm{~mm}$, $D_{4}=36 \mathrm{~mm}$. Damper and liquid film clearance of workpiece respectively are $0.05,0.10,0.15$, and $0.10 \mathrm{~mm}$, damper liquid using emulsion 20\# machine oil. 
The equipment starts and begins to process. The eddy current sensor can be used to detect the vibration of the boring bar. The detected vibration signals are input to the computer through the amplifying circuit and the $\mathrm{AD}$ converter to carry out the data collection and storage.

The whole system is divided into a series of quality unit and elastic rod unit with no quality. The damping unit and power unit with quality units is combined into a special quality unit. So the whole system is composed of quality unit, elastic shaft unit, damp-quality unit, and power-quality unit. The number of the specific units is decided by the required precision. The more the number of units is, the higher the accuracy of the model analysis is (take nine units in this paper).

The lumped parameter system dynamic model is shown in Fig. 1.

In Fig. 1, "F" for exciting force, these five quality units are calculated according to the length, diameter, and density of the boring bar, respectively as follows: $m_{1}=0.385 \mathrm{~kg}$, $m_{2}=0.875 \mathrm{~kg}, m_{3}=0.98 \mathrm{~kg}, m_{4}=0.685 \mathrm{~kg}$, and $m_{5}=0.195 \mathrm{~kg}$.

After the system dynamics model is set up, according to transfer matrix theory, the system mathematical model is established and to solve mathematical model, so as to lay foundation for the establishment of the system simulation model. It is known from the transfer matrix theory that the left and right side system units have a state vector to represent the unit state, denoted as $\mathrm{Zl}$ (left side) and $\mathrm{Zr}$ (right side); the relationship between the state vector can be represented as:

$$
\mathrm{Z}_{1}=\mathrm{CZ}_{\mathrm{r}}
$$

$C$ is a unit transfer matrix or a transfer matrix, and it can be introduced from this: The transfer matrix between any two unit state vectors is multiplied to all unit transfer matrices of the two state vectors. The following is expressed as follows:

$$
\left[\frac{\mathrm{Z}_{1}}{1}\right]=\left[\begin{array}{cc}
\mathrm{C}^{\prime} & \mathrm{F} \\
0 & 1
\end{array}\right]_{\mathrm{i}}\left[\begin{array}{cc}
\mathrm{C}^{\prime} & \mathrm{F} \\
0 & 1
\end{array}\right]_{\mathrm{i}-1} \ldots\left[\begin{array}{cc}
\mathrm{C}^{\prime} & \mathrm{F} \\
0 & 1
\end{array}\right]_{\mathrm{n}+1}\left[\begin{array}{c}
\mathrm{Z}_{\mathrm{r}} \\
1
\end{array}\right]_{\mathrm{n}}
$$

In the formula:

$$
i>n \in I
$$

$C^{\prime}$ is the first four-order square matrices of each transfer matrix.

According to the force balance relations, every each unit can obtain the following transfer matrix.

1. Inelastic quality unit transfer matrix $C_{i m}$

$$
c_{i m}=\left[\begin{array}{ccccc}
1 & 0 & 0 & 0 & 0 \\
0 & 1 & 0 & 0 & 0 \\
0 & 0 & 1 & 0 & 0 \\
m_{i} \omega^{2} & 0 & 0 & 1 & 0 \\
0 & 0 & 0 & 0 & 1
\end{array}\right]
$$

In the formula, $\omega$ is circular frequency.

2. Inelastic mass element transfer matrix $C_{\mathrm{iL}}$

$$
c_{\mathrm{iL}}=\left[\begin{array}{ccccc}
1 & L_{\mathrm{i}} & \frac{L_{\mathrm{i}}^{2}}{2 \mathrm{EI}} & \frac{L_{\mathrm{i}}^{3}}{6 \mathrm{EI}} & 0 \\
0 & 1 & \frac{L_{\mathrm{i}}}{\mathrm{EI}} & \frac{L_{\mathrm{i}}^{2}}{2 \mathrm{EI}} & 0 \\
0 & 0 & 1 & L_{\mathrm{i}} & 0 \\
0 & 0 & 0 & 1 & 0 \\
0 & 0 & 0 & 0 & 1
\end{array}\right]
$$

In the formula, EI is moment of inertia.

3. Damp-quality unit transfer matrix $C_{\mathrm{iF}}$

$$
c_{\mathrm{iC}}=\left[\begin{array}{ccccc}
1 & 0 & 0 & 0 & 0 \\
0 & 1 & 0 & 0 & 0 \\
0 & 0 & 1 & 0 & 0 \\
m_{\mathrm{i}} \omega^{2}+j \omega c & 0 & 0 & 1 & 0 \\
0 & 0 & 0 & 0 & 1
\end{array}\right]
$$

In the formula, $j$ is imaginary unit.

4. Power quality unit transfer matrix $C_{\mathrm{iF}}$

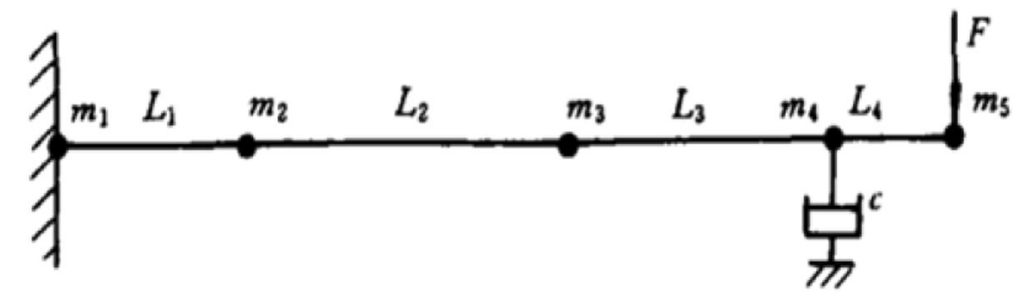

Fig. 1 Boring bar lumped parameter dynamic model 


$$
c_{\mathrm{iC}}=\left[\begin{array}{ccccc}
1 & 0 & 0 & 0 & 0 \\
0 & 1 & 0 & 0 & 0 \\
0 & 0 & 1 & 0 & 0 \\
m_{\mathrm{i}} \omega^{2} & 0 & 0 & 1 & \mathrm{~F} \\
0 & 0 & 0 & 0 & 1
\end{array}\right]
$$

Both sides of system state vector of transfer matrix equations can be concluded by plugging formula 4 into formula 1.

$$
\left\{\begin{array}{c}
\mathrm{Y} \\
\theta \\
\mathrm{M} \\
\mathrm{F} \\
1
\end{array}\right\}_{1}^{1}=C_{1 \mathrm{~m}} C_{1 \mathrm{~L}} C_{2 \mathrm{~m}} C_{2 \mathrm{~L}} \cdots C_{5 \mathrm{~m}}\left\{\begin{array}{c}
\mathrm{Y} \\
\theta \\
\mathrm{M} \\
\mathrm{F} \\
1
\end{array}\right\}_{5}^{\prime}
$$

All the matrices in the formula are both five-order square. $\mathrm{Y}, \theta, \mathrm{M}$, and $\mathrm{F}$ respectively represent the displacement, angle, torque, and force. The left side vector represents left side state vector of the system, and the right side vector represents right side state vector of the system. So the product of the matrix is still 5 square, the $C_{g}$ is as follows:

$$
C_{g}=\left[\begin{array}{ccccc}
C_{11} & C_{12} & C_{13} & C_{14} & 0 \\
C_{21} & C_{22} & C_{23} & C_{24} & 0 \\
C_{31} & C_{32} & C_{33} & C_{34} & 0 \\
C_{41} & C_{42} & C_{43} & C_{44} & F \\
0 & 0 & 0 & 0 & 1
\end{array}\right]
$$

Because the boring bar is closely connected with machine tool axle shaft of Morse taper hole, the system can be as a cantilever beam fixed at one end. So the system boundary conditions are as follows:

$$
Y_{11}=0 \quad \theta_{11}=0 \quad M_{5 r}=0 \quad F_{5 r}=F
$$

The equation can be gotten:

$$
\left\{\begin{array}{l}
0=C_{11} Y_{5}+C_{12} \theta_{5}+C_{14} P \\
0=C_{21} Y_{5}+C_{22} \theta_{5}+C_{24} P
\end{array}\right.
$$

The root of the equation:

$$
Y_{5}=\frac{C_{12} C_{24}-C_{22} C_{14}}{C_{11} C_{22}-C_{12} C_{21}} F
$$

As a result of the existence of system with damping device, $Y_{5}$ is plural

$$
Y_{5}=\zeta_{r}+j \zeta_{i}=\operatorname{Acos}(\omega t+\phi)
$$

In the equation:

$A=\left|\mathrm{Y}_{5}\right|=\sqrt{\zeta_{\mathrm{r}}^{2}+\zeta_{\mathrm{i}}^{2}} \phi=\arctan \frac{\zeta_{\mathrm{i}}}{\zeta_{\mathrm{r}}}$

$\zeta_{\mathrm{r}}-$ - The real part of the complex $Y_{5}$

$\zeta_{\mathrm{i}}-$ - The imaginary part of complex $Y_{5}$
The first one is $Y_{5}$ real part, and the other one is $Y_{5}$ imaginary part.

Through the above model, we know that the system response to external simple harmonic excitation is still the harmonic vibration, the amplitude of response is a function of damping coefficient $c$ and excitation frequency $\omega$, where it can be expressed as:

$$
A=F(C, \omega)
$$

The resonance amplitude is:

$$
A_{\max }=\max F(c, \omega)
$$

\section{Results and discussion}

\subsection{Reliability analysis of the simulation model}

Static test was done under the condition of the machine not working, and vibration adopts the method of external excitation. Its purpose was to test the vibration of the boring bar in the two cases: with damper or not. In the static test, study is done to get the relationship of the damper's parameters and vibration damping effect. The CA6140 lathe was modified to carry boring machining with the boring bar installed in the lathe spindle Morse taper hole [13]. The workpiece was clamped by the fixture and installed on the sliding board. Emulsion and the 20\# machine oil were used as damping liquid respectively. The test data signals was obtained through acceleration sensors, which was sent to a computer to process after signal amplification and A/D conversion. Table 1 is the results with different damping sleeve width and damping fluid (oil) film thickness in the cases with fluid (oil) film and no fluid (oil) film. Trial dampers' inside diameter is $D=60 \mathrm{~mm}$, the absolute liquid viscosity coefficient $\eta=5.949 \mathrm{~Pa} \cdot \mathrm{s}$. The results of the data test are shown in the following Table 1:

An empirical formula for damping coefficient can be got by the relevant parameters of the dampers. It represents the law of the liquid film under the finite long axis in the table.

$$
c=\frac{\eta L R^{3}}{\delta^{3} \mathrm{a}(1-\varepsilon)^{\mathrm{b}}}
$$

In the equation, $R=D / 2$.

$a$ and $b$ are constants associated with damper parameters.

$$
a=0.6(D / L)-0.4, b=1.5+0.3 \sqrt{D / L}
$$

$\delta$ is the damping sleeve and the processing hole clearance value, the thickness of liquid film

$\varepsilon$ is the damper hole with hammer tool rod eccentricity, and its little impact on $c$ so can be ignored. 
Table 1 Field test raw data

\begin{tabular}{|c|c|c|c|c|c|}
\hline \multirow{2}{*}{$\begin{array}{l}\text { Separation } \\
\delta / \mu \mathrm{m}\end{array}$} & \multicolumn{5}{|c|}{ Frequency f/Hz amplitude $\mathrm{A} / \mu \mathrm{m}$} \\
\hline & $\begin{array}{l}\text { The length of } \\
\text { the damper } \\
\mathrm{L} / \mathrm{mm} \\
50\end{array}$ & $\begin{array}{l}\text { The length of } \\
\text { the damper } \\
\mathrm{L} / \mathrm{mm} \\
60\end{array}$ & $\begin{array}{l}\text { The length of } \\
\text { the damper } \\
\mathrm{L} / \mathrm{mm} \\
80\end{array}$ & $\begin{array}{l}\text { The length of } \\
\text { the damper } \\
\mathrm{L} / \mathrm{mm} \\
100\end{array}$ & $\begin{array}{l}\text { The length of } \\
\text { the damper } \\
\mathrm{L} / \mathrm{mm} \\
120\end{array}$ \\
\hline 75 & $1177 / 2.6$ & $1429 / 2.9$ & $1355 / 2.0$ & $1577 / 1.6$ & $1335 / 2.2$ \\
\hline 100 & $1337 / 2.6$ & $1440 / 2.8$ & $1598 / 3.5$ & $1524 / 3.3$ & $1724 / 4.5$ \\
\hline 150 & $1459 / 1.4$ & $1434 / 1.9$ & 1492/1.1 & $1609 / 4.9$ & $1660 / 2.7$ \\
\hline 400 & $1345 / 1.8$ & $1330 / 1.7$ & $1337 / 2.1$ & $1556 / 2.8$ & $1335 / 2.8$ \\
\hline
\end{tabular}

Under the single damping and complex damping, the static test with liquid film and non-liquid film is carried out. Some important data can be measured as shown in Tables 2, 3, and 4 .

From Tables 2, 3, and 4, it can be seen that squeeze liquid (oil) film damper can inhibit the vibration of boring bar no matter in the static excitation or dynamic cutting. In the static test, the effect of liquid film formed by cutting fluid is better than oil film formed by machine oil. In the effect of dynamic test of oil film formed by machine oil is better than liquid film formed by cutting fluid.

From Table 4, it can be seen from all the test data, with the increase of damping sleeve width, the boring bar vibration amplitude was decreased gradually, but when the damping sleeve width continue to increase, the amplitude had a tendency of increase. The change rule can be explained as follows.

From Tables 2, 3, 4, and 5, the test curve of amplitude and resonance frequency with the damping value of number can drew. The curve line is shown in Figs. 3 and 4.
In addition, the curve of the amplitude and the resonant frequency from Eqs. (5), (6) paint and the damping value simulation curve can be shown in Figs. 2 and 3. To be sure, in the simulation study, the size of the force F only affects the position of the curve along the longitudinal axis, does not affect the shape of the curve and the changing trends, and so does not affect the essence of the problem. it can be understand of formula (3). In this case, take $F=1.028 \mathrm{KN}$.

In the Figs. 2 and 3: Both amplitude damping curve and resonance frequency damping curve are very close, and it indicates that the simulation results are basically in agreement with the experimental results; it can be seen that establishing the simulation model is reasonable and reliable.

\subsection{Parameter optimization of damper}

In the design of damper, the main parameters affect the effects of vibration reduction for the thickness $\delta(\mathrm{mm})$ and the length $L(\mathrm{~mm})$ of the liquid film damper. In

Table 2 Single damping oil film, liquid membrane effects on spindle amplitude

\begin{tabular}{|c|c|c|c|c|c|c|c|}
\hline \multirow[t]{2}{*}{ Gap/mm } & \multirow[t]{2}{*}{ Width/mm } & \multicolumn{6}{|c|}{ Amplitude/ $\mu m$} \\
\hline & & Oil film & Non-oil film & Amplitude reduce & liquid film & Non-liquid film & Amplitude reduce \\
\hline \multirow[t]{5}{*}{0.05} & 40 & 96 & 124 & 28 & 104 & 124 & 20 \\
\hline & 60 & 85 & 118 & 33 & 95 & 118 & 23 \\
\hline & 80 & 82 & 109 & 27 & 88 & 109 & 21 \\
\hline & 100 & 76 & 105 & 29 & 82 & 105 & 23 \\
\hline & 120 & 71 & 106 & 35 & 82 & 106 & 24 \\
\hline \multirow[t]{5}{*}{0.10} & 40 & 78 & 120 & 42 & 96 & 120 & 24 \\
\hline & 60 & 73 & 116 & 43 & 86 & 116 & 20 \\
\hline & 80 & 70 & 109 & 39 & 85 & 109 & 24 \\
\hline & 100 & 64 & 104 & 40 & 84 & 104 & 20 \\
\hline & 120 & 63 & 103 & 40 & 81 & 103 & 22 \\
\hline \multirow[t]{5}{*}{0.15} & 40 & 89 & 118 & 29 & 106 & 118 & 12 \\
\hline & 60 & 83 & 112 & 29 & 101 & 112 & 11 \\
\hline & 80 & 84 & 115 & 31 & 97 & 115 & 18 \\
\hline & 100 & 75 & 98 & 23 & 88 & 98 & 10 \\
\hline & 120 & 71 & 92 & 21 & 88 & 92 & 4 \\
\hline
\end{tabular}


Table 3 Single damping oil film, liquid membrane effect on main frequency

\begin{tabular}{|c|c|c|c|c|c|c|c|}
\hline \multirow{2}{*}{$\begin{array}{l}\text { Gap } \\
\text { mm }\end{array}$} & \multirow{2}{*}{$\begin{array}{l}\text { Width } \\
\mathrm{mm}\end{array}$} & \multicolumn{6}{|c|}{ Frequency/Hz } \\
\hline & & oil film & Non-oil film & Amplitude reduce & liquid film & Non-liquid film & Amplitude reduce \\
\hline \multirow[t]{5}{*}{0.05} & 40 & 1419 & 1403 & 16 & 1392 & 1403 & 11 \\
\hline & 60 & 1438 & 1424 & 14 & 1445 & 1424 & 21 \\
\hline & 80 & 1466 & 1424 & 42 & 1450 & 1424 & 26 \\
\hline & 100 & 1516 & 1456 & 60 & 1482 & 1456 & 26 \\
\hline & 120 & 1566 & 1492 & 74 & 1542 & 1492 & 50 \\
\hline \multirow[t]{5}{*}{0.10} & 40 & 1425 & 1389 & 36 & 1419 & 1389 & 30 \\
\hline & 60 & 1450 & 1403 & 47 & 1447 & 1403 & 44 \\
\hline & 80 & 1534 & 1467 & 67 & 1507 & 1467 & 40 \\
\hline & 100 & 1521 & 1426 & 96 & 1536 & 1476 & 40 \\
\hline & 120 & 1607 & 1518 & 89 & 1605 & 1518 & 87 \\
\hline \multirow[t]{5}{*}{0.15} & 40 & 1432 & 1409 & 23 & 1411 & 1409 & 2 \\
\hline & 60 & 1414 & 1392 & 22 & 1416 & 1392 & 24 \\
\hline & 80 & 1455 & 1444 & 11 & 1444 & 1432 & 12 \\
\hline & 100 & 1472 & 1453 & 19 & 1440 & 1453 & 7 \\
\hline & 120 & 1574 & 1524 & 50 & 1553 & 1524 & 29 \\
\hline
\end{tabular}

order to determine the optimal parameters, more groups of dynamic test have been done under the conditions of the actual processing conditions. Because cost is high, the large amount of test is hard to proceed. The law of various parameters on the vibration reduction is analyzed by the simulation model. The results can directly get the optimal parameters, so as to effectively guide field processing.

The $\delta$ value is ensured in a certain range, and the other parameters are constant. Using formula (7) into formula (5), the relation curve of liquid film thicknessamplitude is drew and shown in Fig. 4. In the same way, the liquid film length-amplitude relation curve are drew and shown in Fig. 5.

As seen in Figs. 4 and 5, the optimal thickness of the $\delta$ and the length $L$ of the liquid film damper is 0.1 and $60 \mathrm{~mm}$ respectively. According to the data, the author designed the damping shock absorber, and it has been applied in Dalian Locomotive Plant a TX611C type digital display horizontal boring machine. As the result,

Table 4 Double damping oil film, liquid membrane for the main shaft frequency and amplitude

\begin{tabular}{|c|c|c|c|c|c|c|c|c|c|c|}
\hline \multirow{3}{*}{$\begin{array}{l}\text { Gap/mm } \\
0.05\end{array}$} & \multirow{3}{*}{$\begin{array}{l}\text { Width/mm } \\
40\end{array}$} & \multicolumn{3}{|c|}{ Oil film } & \multicolumn{3}{|c|}{ Liquid film } & \multicolumn{3}{|c|}{ Non-liquid film } \\
\hline & & \multicolumn{2}{|c|}{ Frequency/Hz } & \multirow{2}{*}{$\begin{array}{l}\text { Amplitude/ } \mu \mathrm{m} \\
72.102\end{array}$} & \multicolumn{2}{|c|}{ Frequency/Hz } & \multirow{2}{*}{$\begin{array}{l}\text { Amplitude/ } \mu \mathrm{m} \\
78.107\end{array}$} & \multicolumn{2}{|c|}{ Frequency/Hz } & \multirow{2}{*}{$\frac{\text { Amplitude/ } \mu \mathrm{m}}{83.112}$} \\
\hline & & 1102 & 1518 & & 1114 & 1529 & & 1023 & 1503 & \\
\hline & 60 & 1113 & 1507 & 68.98 & 1098 & 1516 & 70.100 & 1098 & 1464 & 74.106 \\
\hline & 80 & 1132 & 1572 & 60.90 & 1132 & 1582 & 68.92 & 1135 & 1454 & 73.99 \\
\hline & 100 & 1129 & 1602 & 63.86 & 1176 & 1580 & 68.88 & 1097 & 1570 & 66.93 \\
\hline & 120 & 1205 & 1618 & 59.81 & 1212 & 1610 & 60.84 & 1153 & 1592 & 67.85 \\
\hline \multirow[t]{5}{*}{0.10} & 40 & 1016 & 1527 & 71.89 & 1021 & 1521 & 73.91 & 0986 & 1508 & 85.107 \\
\hline & 60 & 1035 & 1556 & 69.80 & 1039 & 1535 & 77.83 & 1024 & 1527 & 86.104 \\
\hline & 80 & 1038 & 1600 & 68.76 & 1056 & 1586 & 72.81 & 1038 & 1580 & 88.96 \\
\hline & 100 & 1096 & 1626 & 60.75 & 1087 & 1603 & 65.78 & 1069 & 1596 & 85.92 \\
\hline & 120 & 1123 & 1633 & 52.68 & 1108 & 1618 & 53.71 & 1123 & 1624 & 79.81 \\
\hline \multirow[t]{5}{*}{0.15} & 40 & 1023 & 1581 & 77.106 & 1009 & 1556 & 79.108 & 1010 & 1545 & 85.116 \\
\hline & 60 & 1034 & 1556 & 74.98 & 1031 & 1567 & 75.99 & 1056 & 1531 & 83.108 \\
\hline & 80 & 1078 & 1595 & 70.89 & 1046 & 1605 & 71.91 & 1035 & 1584 & 79.103 \\
\hline & 100 & 1100 & 1613 & 66.85 & 1106 & 1627 & 70.88 & 1078 & 1615 & 78.99 \\
\hline & 120 & 1135 & 1653 & 60.84 & 1097 & 1632 & 68.85 & 1110 & 1665 & 71.93 \\
\hline
\end{tabular}


Table 5 Cutting, liquid film, and oil film influence on the spindle amplitude

\begin{tabular}{lllll}
\hline Gap/mm & Width/mm & \multicolumn{3}{l}{ Frequency/Hz } \\
\cline { 3 - 5 } & & Oil film & Liquid film & No film \\
\hline 0.05 & 40 & 52 & 56 & 60 \\
& 60 & 49 & 54 & 59 \\
& 80 & 42 & 44 & 52 \\
& 100 & 45 & 45 & 52 \\
& 120 & 51 & 46 & 53 \\
0.10 & 40 & 50 & 54 & 62 \\
& 60 & 47 & 52 & 60 \\
& 80 & 44 & 45 & 55 \\
& 100 & 41 & 46 & 50 \\
& 120 & 40 & 47 & 51 \\
& 40 & 53 & 58 & 61 \\
& 60 & 50 & 54 & 55 \\
& 80 & 43 & 50 & 53 \\
& 100 & 43 & 49 & 52 \\
& 120 & 44 & 48 & 51 \\
\hline
\end{tabular}

the surface roughness has improved to a better vibration damping effect than in the past (seen Fig. 6).

\subsection{Experiment results and discussion}

The tests indicate that no matter what static and under the cutting condition, liquid membrane (including oil film) for boring bar has good vibration

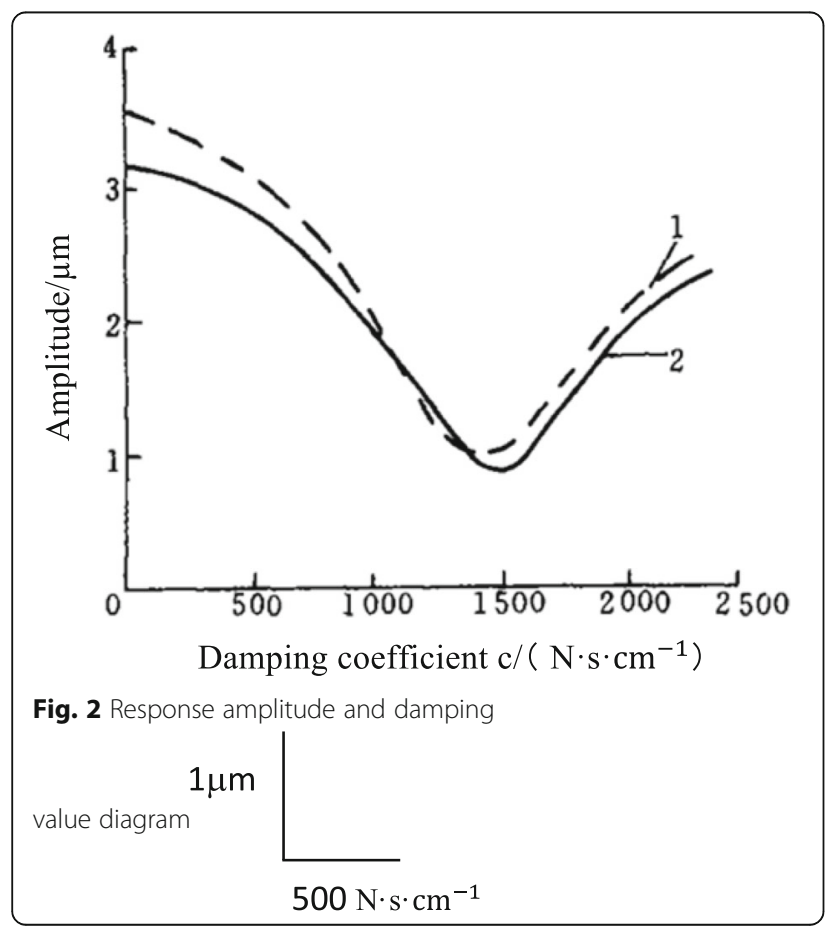

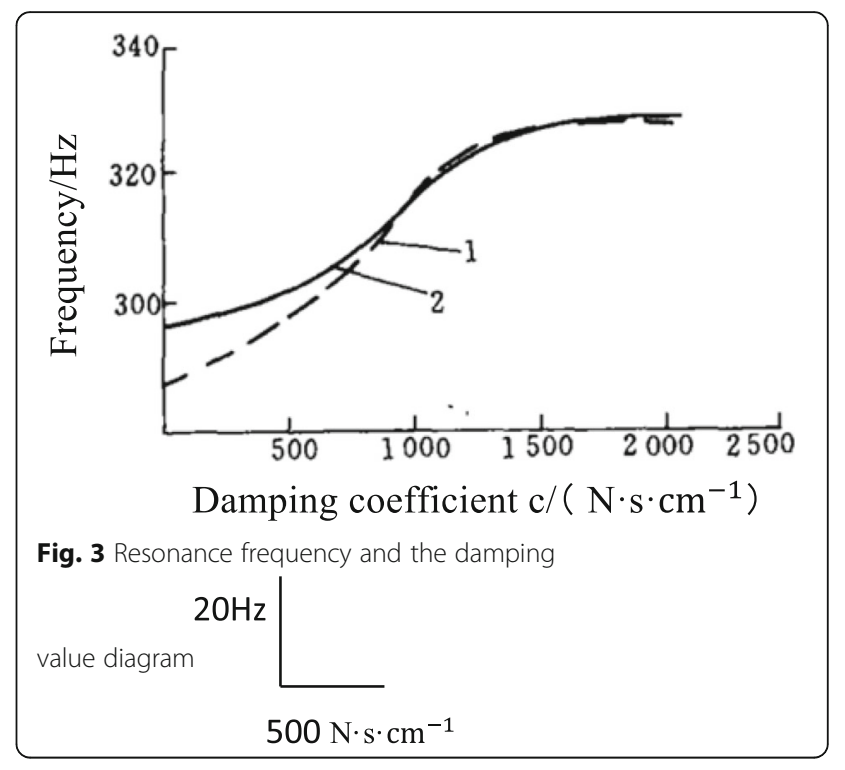

damping effect, the best damping effect at more than $20 \%$. A lot of experimental data show that, when the liquid film thickness and width are 0.1 and $60 \mathrm{~mm}$, respectively, damping effect is best. In simulation, the simulation curve is in agreement with the experimental curve, and it shows the simulation is good and suited for some testing.

The experiment is divided into static and dynamic experiments. In the static experiments, liquid film damper is better than the oil film damper damping effect. In dynamic cutting experiments, the oil film damping effect is better than the liquid film damping effect in general.

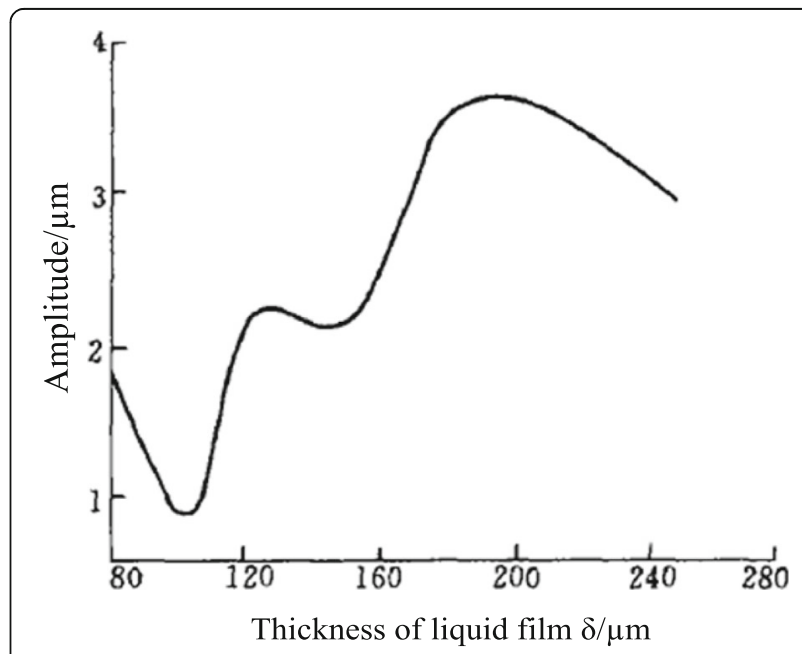

Fig. 4 Liquid film thickness and response amplitude

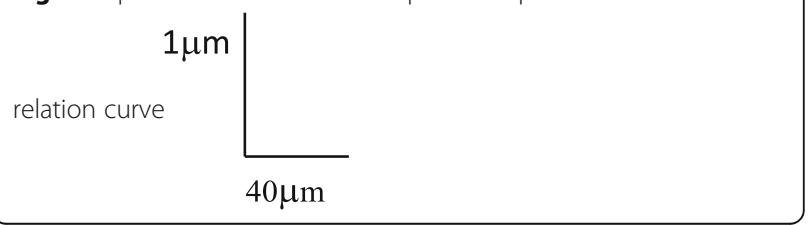




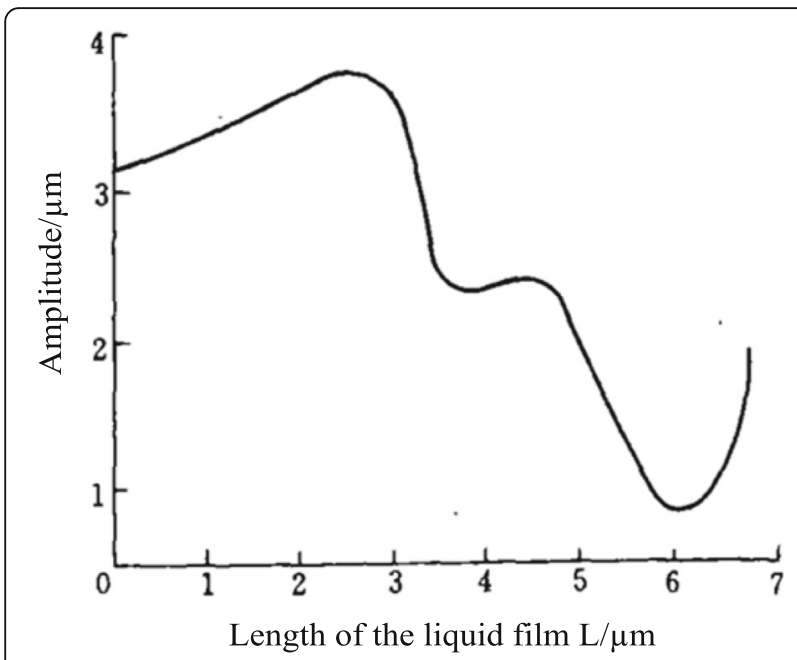

Fig. 5 Liquid film lengths and response amplitude

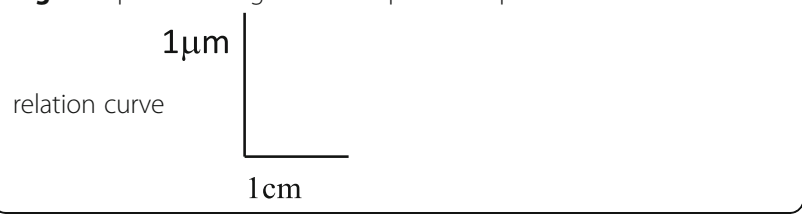

Fine boring liquid film damping system can greatly improve the machine tool dynamic stiffness and cutting vibration resistance, while not reducing other performance indicators. It has a simple structure and reliable performance.

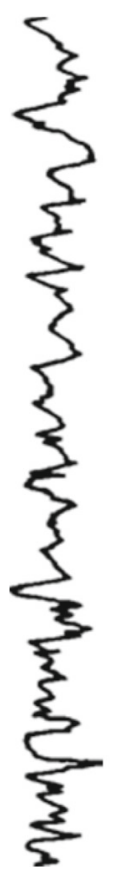

(a) No liquid film damper

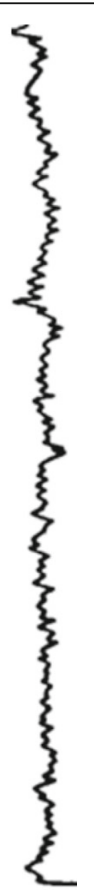

(b) Liquid film damper
Fig. 6 Surface roughness measuring results

\section{Conclusions}

This paper presented an experimental study on fine boring squeezed liquid film damped system, and setting up a freedom vibration simulation model. Some mathematical model can be solved by transfer matrix theory. The mechanical device of a liquid film damping system is established. 20\# machine oil, 40\# machine oil, and cutting fluid are used to the system. The following conclusions can be drawn from this study.

1. The damping coefficient for the fine boring system can be obtained.

2. Using multi degree of freedom system vibration simulation model to analyze the squeeze liquid film damping system has high reliability and accuracy.

3. Using the simulation model can reduce the test cost, direct access to optimize parameters of shock absorber on the basis of parameter design and manufacture of shock absorber, and bring good effect in practice.

\section{Acknowledgements}

The research presented in this paper is supported by Dalian Minzu University and State ethnic Affairs Commission of China.

\section{Funding}

The authors acknowledge the Fundamental Research Funds for the Central Universities (Grant: DC201502010305), Liaoning Provincial Natural Science Foundation of China (Grant: 201602196).)

\section{Authors' contributions}

QShao is the main writer of this paper. He proposed the main idea, deduced the performance of liquid film damper, completed the simulation, and analyzed the result. LWang introduced the liquid film damper for testing. DWang simulated the liquid film damper by soft. P-SGe gave some important suggestions for the liquid film damper. All authors read and approved the final manuscript.

\section{Competing interests}

The authors declare that they have no competing interests.

\section{Publisher's Note}

Springer Nature remains neutral with regard to jurisdictional claims in published maps and institutional affiliations.

\section{Author details}

${ }^{1}$ College of Mechanical and electronic Engineering, Dalian Minzu University, Dalian 116600, China. ${ }^{2}$ College of Engineering Education, Dalian Minzu University, Dalian 116600, China. ${ }^{3}$ Key laboratory of Intelligent Perception and Advanced Control of State Ethnic Affairs Commission, Dalian 116600, China.

Received: 9 March 2018 Accepted: 30 May 2018

Published online: 11 June 2018

\section{References}

1. H Sasaki, N Ochiai, Y Iga, Numerical analysis of damping effect of liquid film on material in high speed liquid droplet impingement. Int J Fluid Machine Syst 9(1), 57-65 (2016)

2. Y Matsumura, T Shiraishi, S Morishita, Stiffness and damping of liquid crystal lubricating film under electric field. Tribol. Int. 54, 32-37 (2012).

3. Shao Qiang, Song Peng, Feng Changjian. Faults diagnosis for vibration signal based on HMM, Sensors \& Transducers, 165(2) ,8-15(2013).

4. S Qiang, S Jia-Heng, T Xiao-Mei, Study on application of squeeze film damper in precision hole grinding. J. Comput. Theor. Nanosci. 13, 58675871 (2016) 
5. S Qiang, Fine boring liquid film damping technique experiment research (Dalian Railway University, Dalian, 2001).

6. Z Yong-cheng, H Hongbiao, Y Changgang, Z Liang, Simulation of liquidfilm-damping system in machining of precise borehole. Chin. J. Mechanic. Eng. 39(8), 151-154 (2003).

7. Yu tian-biao, Gong Ya-dong, Jiang zao, Wang Wan-shan. Study on application of squeeze film damper in precision hole grinding. Chin. J. Mechanic. Eng., v39,n12, 114-117, 122 (2003).

8. Y-m Li, Xiao-kui, Research on deep hole drilling chatter control based on film damper. Mod. Mach. Tool Auto. Manufact. Techn. 4, 57-59 (2014).

9. R-G Xu, Y Leng, Contact stiffness and damping of liquid films in dynamic atomic force microscope. J. Chem. Phys. 144(15), 21-30 (2016).

10. F Antoine, S Matthew, C Hua, H Christopher, H Kai, M Frederic, M Bruno, Experimental observation of inertia-dominated squeeze film damping in liquid. J. Fluids Eng. Trans. ASME 132(12), 156-165 (2010).

11. Zhao, Shiquan, Zhu, Dan-Hui, Qi, Yongxing, Chen, Hualing. Experiment on vibration reducing capacities of pore viscous damping and liquid film damping. Adv. Mater. Res. v430-432, p1822-1825(2012).

12. S Huang, B-T Diana-Andra, T John, Liquid squeeze film damping in microsystems applications. ICNMM 2010, 885-886 (2010).

13. S Qiang, H Hong-ying, L Wen-long, Study on method of chatter recognition based on EMD and SVM. Coal Mine Machinery 38(02), 68-70 (2017).

\section{Submit your manuscript to a SpringerOpen ${ }^{\circ}$} journal and benefit from:

- Convenient online submission

- Rigorous peer review

- Open access: articles freely available online

- High visibility within the field

- Retaining the copyright to your article

Submit your next manuscript at $\gg$ springeropen.com 